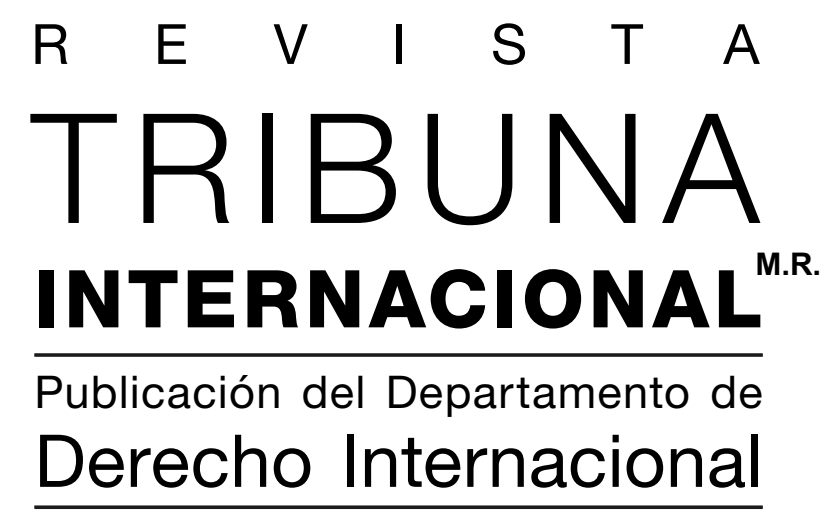

Volumen $4 / N^{\circ} 7 / 2015$

DERELTAD DE

UNIVERSIDAD DE CHILE 


\section{Rector de la Universidad de Chile}

Ennio Vivaldi Véjar

Av. Alameda Libertador Bernardo

O’Higgins 1058, Santiago

Representante legal

Davor Harasic Yaksic

Decano de la Facultad de Derecho

Universidad de Chile

Director del Departamento de

Derecho Internacional

Edmundo Vargas Carreño

Director de la Revista Tribuna

Internacional

Mario Ramírez Necochea

Editor General de la Revista Tribuna

Internacional

Luis Valentín Ferrada Walker

\section{Comité Editorial}

Íñigo Álvarez Gálvez (Universidad de Chile, Chile)

Gonzalo Aguilar (Universidad de Talca, Chile)

José Carlos Fernández Rosas

(Universidad Complutense de Madrid,

España)

Claudio Grossman (American

University, EE.UU)

Mattias Kumm (New York University,

EE.UU)

Hugo Llanos (Universidad Central, Chile)

Cecilia Medina (Universidad Diego

Portales, Chile)

Elina Mereminskaya (Universidad de Chile, Chile)

Mónica Pinto (Universidad de Buenos Aires, Argentina)

\section{Revista Tribuna Internacional M.R.}

Publicación del Departamento de Derecho Internacional de la Facultad de Derecho de la Universidad de Chile. $\mathrm{Su}$ objetivo es fomentar la reflexión, el debate, el análisis y la comunicación sobre el derecho internacional en forma pluralista y con rigor científico. Se publica cada semestre en los meses de junio y diciembre mediante convocatoria abierta a la publicación de artículos y monografías inéditos, comentarios de jurisprudencia, recensiones y comentarios de libros, en los campos de derecho internacional público y privado, derecho internacional de los derechos humanos y relaciones internacionales, tanto en castellano como en inglés.

Volumen 4/ No 7 / 2015

www.tribunainternacional.uchile.cl

ISSN 0719-210X (versión impresa)

ISSN 0719-482X (versión en línea)

Departamento de Derecho Internacional Facultad de Derecho

Universidad de Chile

Av. Santa María 076, $4^{\circ}$ piso

Providencia, Santiago de Chile

\section{Diseńo y producción:}

Gráfica LOM

www.lom.cl

Impreso en Chile/ Printed in Chile

Se autoriza la reproducción total o parcial del contenido de la publicación, siempre que se reconozca y cite el/ la/ los/ las autor/a/es/as y la publicación, no se realicen modificaciones a la obra y no se la utilice para fines comerciales. 
Revista Tribuna Internacional

Volumen $4 \cdot \mathrm{N}^{0} 7 \cdot 2015 \bullet$ pp. 109-128

ISSN 0719-210X (versión impresa)/ISSN 0719-482X (versión en línea)

\title{
Los argumentos estadounidenses para justificar el uso de la fuerza contra el Estado Islámico ${ }^{1}$
}

\author{
The US arguments to justify the use of force against the Islamic \\ State
}

\section{Giancarlo Mosciatti Gómez}

gcmosciatti@gmail.com

Abogado, Universidad de Chile. Máster en Derecho Internacional y Europeo, Université Pierre-Mendès-France (UPMF), Grenoble, Francia. Diplomático en formación en la Academia Diplomática Andrés Bello, Chile.

Resumen: El presente artículo examina los argumentos esgrimidos en la Joint Resolution presentada por el Presidente de los Estados Unidos, Barack Obama, al Congreso norteamericano para emplear el uso de la fuerza en contra del denominado Estado Islámico. En general, la Carta de las Naciones Unidas prohíbe el uso y la amenaza de la fuerza contra la integridad territorial o la independencia política de cualquier Estado, salvo las dos excepciones que contempla: el sistema de seguridad colectiva de Naciones Unidas y el derecho de la legítima defensa. Sin embargo, Estados Unidos invoca, tanto expresa como tácitamente, otras excepciones, a saber, la determinación de una amenaza para la paz y seguridad internacionales, la legítima defensa para proteger a sus civiles y nacionales, la intervención por invitación o con el consentimiento del Estado afectado y, finalmente, la Responsabilidad de Proteger. Este artículo busca demostrar la hipótesis de que estos argumentos no tienen asidero en el Derecho Internacional, manteniéndose exclusivamente aquellas excepciones contempladas por la Carta de Naciones Unidas.

Palabras claves: uso de la fuerza, legítima defensa, Responsabilidad de Proteger y Estado Islámico.

Abstract: This paper examines the arguments of the Joint Resolution presented by the President
of the United States, Barack Obama, to the United States Congress to employ the use of force
against the so-called Islamic State. Overall, the UN Charter prohibits the use and threat of force
against the territorial integrity or political independence of any state, except the two exceptions:
the collective security system of the United Nations and the right of self-defense. However, the
United States invoked, either expressed or implied, other exceptions, namely the determination of
a threat to international peace and security, self-defense to protect their civilians and nationals,
the intervention by invitation or with the consent of the State concerned and, finally, the Respon-
sibility to Protect. This paper seeks to prove the hypothesis that these arguments have no basis in
international law, keeping only those exceptions provided by the UN Charter.

Keywords: Use of force, Self-defense, Responsibility to Protect, Islamic State.

1 Artículo enviado el 27.03.2015 y aceptado el 19.05.2015. 


\section{Introducción}

El 11 de febrero de 2015, el Presidente de los Estados Unidos, Barack Obama, solicitó al Congreso norteamericano aprobar la disposición "Joint resolution. To authorize the limited use of the United States Armed Forces against the Islamic State of Iraq and the Levant" (en adelante, la Joint resolution), que autoriza el uso de la fuerza contra el denominado Estado Islámico (EI) ${ }^{2}$.

El Estado Islámico en Irak y el Levante es un movimiento yihadista sunnita fundado en Irak. Sus orígenes se remontan al ańo 2004, cuando el jordano Abu Musab al Zarqaui se proclama líder de Al-Qaeda en Mesopotamia para luchar contra la ocupación estadounidense en Irak llevada a cabo por el ex Presidente George W. Bush. Tras la muerte de al Zarqaui en 2006, el movimiento resurge en Irak en 2007 bajo el nombre de Estado Islámico. Sin embargo, debido a los combates contra el ejército estadounidense, el ejército iraquí y algunas milicias sunnitas, el EI debe replegarse a las regiones fronterizas con Siria.

Aprovechando la guerra civil iniciada en 2011 en Siria entre los partidarios del Presidente Bashar Al-Asad -perteneciente a una minoría demográfica del país, los alawí, enmarcados dentro del chiismo- y los rebeldes -provenientes de la mayoría sunnita-, el EI se replegó en dicho Estado. Posteriormente, en 2013, el EI envía hombres a combatir al norte de Siria, adoptando una nueva denominación: Estado Islámico de Irak y el Levante (EIIL), logrando imponerse en varias ciudades sirias, especialmente en Rakka. Por otro lado, el gobierno chiita iraquí, liderado en ese entonces por Nuri Al-Maliki, busca debilitar a las poblaciones de la mayoría sunnita las que, en 2013, se sublevan. Se abre entonces el camino para que el EIIL pueda retornar con fuerza en Irak.

Hacia mediados de 2014, el EIIL controlaba buena parte del occidente y centro de Irak. El apoyo y la fuerza que tiene el EIIL se explica -en parte- por el respaldo brindado por las mayorías sunnitas frente a los gobiernos chiitas a la cabeza de Damasco y Bagdad. En junio de 2014, el EIIL cambia su denominación a Estado Islámico cuando su líder, Abu Bakr al-Baghdadi, se autoproclama Califa del Estado Islámico. Desde entonces, el Estado Islámico ha reclutado a miles de combatientes provenientes de diversas partes del mundo.

2 Para información más detallada sobre el EI, vid. NAYouf, Mamduh. "État Islamique-2009-2014: Les rendez-vous manqués de Barak Obama", en Le courrier du Maghreb et de l'Orient, octubre del 2014. [en línea] <http://lecourrierdumaghrebetdelorient.info/headline/etat-islamique-2009-2014-les-rendez-vousmanques-de-barak-obama/> [consulta: 10 de junio del 2015]; AL-Tamimi, Aymenn Jawad. "The Dawn of the Islamic State of Iraq and ash-Sham”, en Middle East Forum, 27 de enero del 2014. [en línea] <http:// www.meforum.org/3732/islamic-state-iraq-ash-sham> [consulta: 10 de junio del 2015]. 
Revista Tribuna Internacional

Volumen $4 \cdot \mathrm{N}^{0} 7 \cdot 2015 \bullet$ pp. 109-128

ISSN 0719-210X (versión impresa)/ISSN 0719-482X (versión en línea)

Contra esta organización, el Presidente Obama presentó la Joint resolution, basada en cuatro puntos esenciales ${ }^{3}$ :

1. Autorización por el plazo de tres años.

2. Dirigido contra el Estado Islámico y “las fuerzas y personas asociadas”.

3. Dado lo anterior, geográficamente no se ceñirá únicamente a los territorios de Siria e Irak.

4. Limitación: las operaciones ofensivas durables de combate en tierra están prohibidas.

Este documento llama la atención por diversos motivos. En primer lugar, busca diferenciarse de su antecesor, el ex Presidente George W. Bush, y las malas experiencias relacionadas con las intervenciones armadas en Afganistán e Irak basadas en la doctrina de la legítima defensa preventiva ${ }^{4}$. Por lo demás, no se busca iniciar una nueva guerra de grandes proporciones como las recién mencionadas, aunque se autorizarían operaciones de reconocimiento, de rescate y raids de fuerzas especiales contra los jefes del EI.

En segundo lugar, si bien existe una aparente limitación temporal auto-impuesta de tres años desde la autorización por parte del Congreso, se señala en el mismo documento que dicha duración regirá "a menos que sea reautorizada". En otras palabras, en principio la intervención militar sería de un plazo de tres ańos pero puede ser ampliada mediando una nueva autorización del Congreso norteamericano.

En tercer lugar, los objetivos visados se dirigen contra el Estado Islámico y "las fuerzas y personas asociadas". Esto incluye a "las personas y organizaciones que luchan por, en nombre de o junto al EI o cualquier entidad sucesora estrechamente relacionada en las hostilidades contra Estados Unidos o sus socios de la coalición”" La subjetividad y parcialidad de la atribución de esas calidades a ciertos individuos u organizaciones resulta evidente.

3 El documento presentado por el Presidente Obama al Congreso norteamericano puede consultarse [en línea] $<$ https://s3.amazonaws.com/s3.documentcloud.org/documents/1658883/text-of-obamas-resolution-toauthorize-military.pdf> [consulta: 10 de junio del 2015].

4 La legítima defensa preventiva se anticipa a un eventual ataque armado, bastando la simple amenaza de ataque. Por otro lado, la legítima defensa interceptiva busca contener un ataque armado ya iniciado. La primera de ellas fue justamente la llevada a cabo por el Presidente Bush en dichas intervenciones armadas bajo las denominadas "guerra preventiva" y "guerra contra el terrorismo". Para mayor información, vid. Kolb, Robert. "Self-defense and preventive war at the beginning of the Millennium". Zeitschrift für öffentliches Recht. Vol. 59. Viena, 2004, pp. 111-134; Murphy, Sean D. "The doctrine of preemtive selfdefense”, en George Washington University Law School, Legal Studies Research Paper Series. 2005 [en línea] $<$ http://papers.ssrn.com/sol3/papers.cfm?abstract_id=707523\#\#> [consulta: 10 de junio del 2015]; GrAY, Christine. "The US National Security Strategy and the 'New Bush Doctrine' on Preemtive Self-defense". Chinese Journal of International Law. 2002, pp. 437-447; Dubuy, Mélanie. La 'guerre préventive' et l'évolution du droit international public. París, Documentation Française, 2012, 706 p.

5 Sección 5 de la Joint resolution. 
Finalmente, el territorio en que se llevarán a cabo las intervenciones militares puede exceder aquellos de Siria e Irak. Esto presenta varias dificultades que se expondrán posteriormente.

Con todo, el documento presentado por el Presidente Obama deja entrever a lo menos cuatro elementos que intentan enmarcar, dentro de los márgenes lícitos establecidos en el régimen internacional del uso de la fuerza, las acciones militares para combatir al Estado Islámico en los mencionados territorios. En efecto, la Joint Resolution alude al uso de la fuerza y la determinación de una amenaza para la paz (I), al derecho inmanente de legítima defensa, particularmente la invocación de aquella para proteger a sus civiles y nacionales (II), la intervención por invitación o con el consentimiento del Estado afectado (III), y, finalmente, un guiño a la intervención humanitaria (IV). La hipótesis de este artículo es que estos argumentos no tienen asidero en el Derecho Internacional, manteniéndose exclusivamente aquellas excepciones contempladas expresamente por la Carta de Naciones Unidas.

\section{El uso de la fuerza y la determinación de una amenaza para la paz y seguridad internacionales}

La Joint Resolution señala expresamente que el Estado Islámico "supone una grave amenaza para las personas y la integridad territorial de Irak y Siria, la estabilidad regional y los intereses de seguridad nacional de los Estados Unidos y sus aliados y socios". La importancia de esta calificación es que conlleva la eventual aplicación de medidas -incluyendo el uso de la fuerza- que podrían ser adoptadas.

Antes que todo, la Carta de las Naciones Unidas (en adelante "la Carta") estableció en su art. 2(4) una prohibición general a la amenaza y al uso de la fuerza -y por ende lógicamente también la guerra-, como medios de solución de controversias internacionales, lo que fue confirmado por la Corte Internacional de Justicia en el caso del Estrecho de Corfú $u^{6}$. Por lo demás, la regla establecida en el art. 2(4) tiene un origen consuetudinario, tal como fue reconocido por las partes en el Caso de las actividades militares y paramilitares en Nicaragua y contra Nicaragua de $19866^{7}$, así como su naturaleza de ius cogens ${ }^{8}$, la que hoy no es discutida por nadie.

Con todo, la determinación de una situación de "amenaza para la paz y la seguridad internacionales" es de competencia exclusiva del Consejo de Seguridad de Naciones

CIJ (1949). Asunto del Estrecho de Corfú, p. 35.

CIJ (1986). Caso de las actividades militares y paramilitares en Nicaragua y contra Nicaragua, párr. 190.

Gómez, Antonio. El ius cogens internacional: Estudio histórico-critico. $1^{\text {a }}$ reimpresión. México D.F., Universidad Nacional Autónoma de México - Instituto de Investigaciones Jurídicas, 2003, 227 p. 
Revista Tribuna Internacional

Volumen $4 \cdot \mathrm{N}^{0} 7 \cdot 2015 \bullet$ pp. 109-128

ISSN 0719-210X (versión impresa)/ISSN 0719-482X (versión en línea)

Unidas. En efecto, la Carta prevé un mecanismo de acción para hacer frente a casos de amenazas o quebrantamientos de la paz o derechamente actos de agresión, los que se encuentran establecidos en los capítulos VI y VII, pudiendo adoptar diferentes medidas en los diversos escenarios posibles:

Si la continuación de una controversia puede poner en peligro la paz, el Consejo de Seguridad puede hacer recomendaciones para resolver esa controversia (arts. 36 y 37), incluida la investigación de la controversia (art. 34).

Si el conflicto o controversia pasa a constituir una amenaza a la paz, el Consejo puede hacer recomendaciones a las Partes para que cumplan con las medidas provisionales que juzgue necesarias (arts. 39 y 40).

Si el conflicto desemboca en un quebrantamiento de la paz, puede aplicar el capítulo VII de la Carta, incluidas medidas coercitivas que signifiquen el uso de la fuerza?.

La Carta no seńala cuándo se encuentra amenazada o quebrada la paz ni tampoco qué se entiende por agresión ${ }^{10}$. Sin embargo, es precisamente el Consejo de Seguridad el órgano llamado a definirlas de acuerdo al mandato expreso del art. 39, según el cual la calificación que haga del hecho o de la situación es una condición sine qua non para la aplicación del capítulo VII de la Carta y de las medidas o sanciones que pudiesen adoptarse. Habiendo determinado y calificado el hecho, el Consejo de Seguridad puede instar a las partes interesadas a que cumplan con las medidas provisionales que juzgue necesarias o aconsejables, las que no deberán perjudicar los derechos, las reclamaciones o la posición de las partes interesadas, tomando nota por lo demás del incumplimiento de éstas (art. 40).

Si las circunstancias lo ameritan, el Consejo de Seguridad podrá decidir "medidas que no impliquen el uso de la fuerza armada" para hacer efectivas sus decisiones, tales como "la interrupción total o parcial de las relaciones económicas y de las comunicaciones ferroviarias, marítimas, aéreas, postales, telegráficas, radioeléctricas, y otros medios de comunicación, así como la ruptura de relaciones diplomáticas” (art. 41).

En caso de que estas medidas que no implican el uso de la fuerza armada resulten ser "inadecuadas o han demostrado serlo, (el Consejo) podrá ejercer, por medio de fuerzas aéreas, navales o terrestres, la acción que sea necesaria para mantener o restablecer la paz y la seguridad internacionales", como por ejemplo "demostraciones, bloqueos y otras operaciones ejecutadas por fuerzas aéreas, navales o terrestres de Miembros de las Naciones Unidas" (art. 42).

9 FigueroA, Uldaricio. Organismos Internacionales: Funcionamiento y Actividades. Santiago, Editorial LexisNexis Cono Sur, 2002, p. 84.

10 La agresión está definida en la Resolución 3314 (XXIX) de la Asamblea General de Naciones Unidas, a la que se hará referencia posteriormente. 
La Carta entonces establece una especie de orden de prelación respecto a las medidas que puede adoptar, dependiendo de la situación a la que se vea enfrentada: primero, deberá proponer e instar al cumplimiento de medidas provisionales; segundo, puede decidir el empleo de medidas que no impliquen el uso de la fuerza armada; y, tercero, sólo en caso de demostrarse que estas medidas pueden ser inadecuadas o han demostrado serlo, podrá ejercer medidas que sí impliquen el uso de la fuerza, con el objetivo de mantener o restablecer la paz y la seguridad internacionales.

Por lo tanto, la ONU cuenta efectivamente con un mecanismo de disuasión propio, el que debe operar en situaciones que determine el Consejo de Seguridad ${ }^{11}$. No obstante, la calificación del art. 39 de la Carta no produce, por sí sola, efectos jurídicos. Si el Consejo de Seguridad no adopta sanciones ni medidas, "la constatación de una amenaza contra la paz o de una ruptura de la paz queda limitada al nivel político", no pudiendo interpretarse su inacción como una autorización tácita ${ }^{12}$.

\section{La legítima defensa para la protección de nacionales}

La Joint Resolution hace una referencia expresa a la protección de los nacionales al señalar que "los líderes del Estado Islámico han declarado su intención de conducir ataques terroristas internacionalmente, incluyendo ataques contra los Estados Unidos, sus ciudadanos y sus intereses", responsabilizándolos de la muerte de los ciudadanos estadounidenses James Foley, Steven Sotloff, Abdul-Rahman Peter Kassig y Kayla Mueller.

La legítima defensa corresponde a una de las excepciones al principio general de la prohibición del uso y amenaza de la fuerza en el Derecho Internacional y está expresamente contemplada en el art. 51 de la Carta, correspondiendo a una respuesta lícita de un Estado ante la agresión de otro Estado ${ }^{13}$.

En términos generales, la legítima defensa "es el estado de aquel que, por encontrarse en la necesidad de defenderse de un acto de agresión, comete un acto, en principio, prohibido por la ley", siendo lo legítimo "lo que reúne los requisitos ordenados por la ley, en este caso una agresión injusta, y que para repelerla se utilicen medios proporcionados para defenderse (...)"14. A mayor abundamiento, la doctrina ha establecido

11 Tettamanti, Pablo Anselmo. Uso de la fuerza en los conflictos internacionales: Un análisis al final del bipolarismo. Buenos Aires, Editorial Universidad, 1995, p. 57.

12 Sicilianos, Linos-Alexandre. "Entre multilatéralisme et unilatéralisme: L'autorisation par le Conseil de sécurité de recourir à la force”. Recueil des Cours, vol. 339. La Haya, Académie de Droit International, 2008, pp. 44-45.

13 Dromi, Laura. Legítima defensa internacional. Buenos Aires, Ciudad Argentina, 1998, p. 10.

14 Oyarte, Rafael. La legitima defensa en el Derecho Internacional. Quito, Pontificia Universidad Católica del 
Revista Tribuna Internacional

Volumen $4 \cdot \mathrm{N}^{0} 7 \cdot 2015 \bullet$ pp. 109-128

ISSN 0719-210X (versión impresa)/ISSN 0719-482X (versión en línea)

ciertos elementos que serían constitutivos o propios de la legítima defensa en el Derecho Internacional, a saber:

i) Actual agresión ilegítima: La Resolución 3314 (XXIX) de la Asamblea General de la ONU de 1974 establece una definición de la agresión, entendida como "el uso de la fuerza armada por un Estado contra la soberanía, la integridad territorial o la independencia política de otro Estado, o en cualquier otra forma incompatible con la Carta de las Naciones Unidas" (art. 1). Adicionalmente, "el primer uso de la fuerza armada por un Estado en contravención de la Carta constituirá prueba prima facie de un acto de agresión (...)" (art. $2^{\circ}$ ), enumerando una serie de actos no taxativos $\left(\right.$ arts. $3^{\circ}, 4^{\circ}$ y $\left.6^{\circ}\right)$ que, independientemente de que haya declaración de guerra o no, se caracterizan como actos de agresión.

Sin embargo, no cualquier agresión puede ser respondida por la fuerza. Por ejemplo: "un acto contra la bandera de un Estado por parte de otro puede producir un grave incidente diplomático, pero no puede ser óbice para que el Estado cuyo pabellón nacional fue ofendido tome acciones de tipo bélico en contra de quien lo produce"15. Además, la agresión tampoco se limita sólo a un uso de la fuerza armada ya que habla de "cualquier forma incompatible con la Carta, que afecte la integridad territorial, soberania e independencia de una nación".

ii) Necesidad de ejercer la acción: Algunos autores plantean este requisito que, en general, implica la necesidad de defenderse cuando si no se realiza alguna acción hay un riesgo cierto de que por causa de una agresión se pierda un bien propio ${ }^{16}$.

En realidad se trata más bien de una racionalidad de los medios empleados o, si se quiere, la "necesidad de actuar conforme al Derecho Internacional", más que una "necesidad de actuar en legítima defensa", ya que de lo contrario, el Estado víctima se convertiría en un Estado agresor y trasgresor del Derecho Internacional.

iii) Racionalidad del medio empleado para repeler la agresión: La respuesta "no debe exceder (...) el medio empleado por el agresor en su acción ilegítima"17, es decir, la respuesta debe poseer la característica de proporcionalidad. Para ciertos autores, se debe tener en cuenta cuáles son los medios con los que cuenta el Estado para poder defenderse, aunque muchas veces esta información no es pública.

Ecuador, 1998, p. 39.

15 Oyarte, La legitima defensa..., op.cit., p. 42.

16 Ortega, Martín. La legítima defensa del territorio del Estado: Requisitos para su ejercicio. Madrid, Tecnos, 1991, p. 33.

17 Oyarte, La legítima defensa..., op.cit., pp. 49 y 50. 
En todo caso, y de acuerdo a los principios establecidos en la Carta, en la medida de lo posible se deben priorizar los métodos de solución de controversias pacíficos por sobre una respuesta armada, la cual debe ser la ultima ratio.

iv) Falta de provocación suficiente: Este elemento de la legítima defensa se relaciona íntimamente con la existencia de una agresión ilegítima que, por lo mismo, viola el Derecho Internacional. Si el ataque armado fue provocado previamente por quien lo sufre, no podríamos hablar que el Estado atacante está cometiendo un acto de agresión, puesto que su acción podría enmarcarse dentro de la legítima defensa. Por lo mismo, será necesario analizar si la agresión no fue provocada anteriormente por el Estado agredido, la que, en todo caso, debe ser suficiente.

v) Inmediatez: Este elemento implica que la acción en respuesta a la agresión inicial no se extralimite en el tiempo puesto que, en caso contrario, el fin defensivo no se cumple, pues no hay un "emparejamiento teleológico entre el acto violento y el ataque injusto, con lo que el acto violento adquiere otra finalidad, como por ejemplo hacer justicia, o simplemente venganza, finalidades que en la actualidad ya no son aceptadas por el Derecho"18.

En la práctica internacional existe un elemento relevante para poder determinar la inmediatez: la premeditación. Las operaciones premeditadas no cumplen con el requisito de la inmediatez, por lo tanto esas acciones estarían enmarcadas no dentro de una acción en legítima defensa, sino que dentro de las denominadas represalias armadas, las que se encuentran prohibidas por el Derecho Internacional.

Sin embargo, la Joint Resolution invoca la legítima defensa para la protección de nacionales, que corresponde a una de las nociones más difíciles y complejas de argumentar y concebir. Teóricamente, esta noción se refiere a la realización de ciertos actos dirigidos contra los nacionales de un Estado en el extranjero, los cuales se entienden o subentienden dirigidos contra el Estado mismo y, por ende, un ataque armado dirigido contra ese Estado, lo que permitiría la entrada en operación de la legítima defensa.

Son varios los problemas que se pueden identificar. Primero se debe distinguir entre los actos dirigidos contra los nacionales de un Estado en el extranjero y los actos dirigidos contra el Estado en sí. Segundo, se debe diferenciar si se trata de actos efectuados por bandas terroristas o grupos armados irregulares, o bien corresponden a disturbios internos o de violencia generalizada. Tercero, la prueba de la atribución de dichos actos a un Estado, de modo tal que puedan considerarse como un ataque armado en los términos de la Carta de Naciones Unidas. Finalmente, la calificación unilateral que el Estado afectado puede realizar sin sustento.

18 Ortega, La legitima defensa..., op.cit., p. 38. 
Al tratar de extender la noción de agresión armada no definida en el art. 51 de la Carta, se amplía indirectamente el alcance de dicha disposición. Empero, tal asimilación ficticia no resulta convincente por varias razones. En primer término, esta equiparación no se planteó en el seno del Comité Especial para la Definición de la Agresión, "pues ninguno de los tres proyectos llevados al Comité en 1969 contenía referencia alguna a ampliar la noción de agresión en tal sentido, a pesar de otras propuestas que tenían esa finalidad y, además, ninguno de los Estados intervinientes se pronunció en el sentido de considerar un atentado contra los nacionales como una agresión armada dirigida contra su soberanía”. En segundo término, "como la práctica (...) pone de manifiesto la puesta en peligro de la vida de los nacionales en el extranjero, no parece reunir las características que definen a un ataque armado" 19 .

La legítima defensa para la protección de nacionales y, en definitiva, para justificar intervenciones militares, ha sido invocada en diversas ocasiones. Por ejemplo ${ }^{20}$, en 1956, por parte de Gran Bretaña por el asunto del Canal de Suez ${ }^{21}$, cuando el Canciller de la época, Lord Kilmuir, señaló que la intervención se encuentra justificada cuando exista un "peligro inminente de daño a los nacionales", producto del fracaso o la incapacidad del soberano territorial para protegerlos ${ }^{22}$.

Otro ejemplo ocurrió en la denominada "Operación Entebbe", que tuvo lugar el 3 y madrugada del 4 de julio de 1976 en el aeropuerto internacional de Entebbe, en Uganda. El 27 de junio de ese año, el vuelo Air France Tel-Aviv-París fue secuestrado por cuatro individuos y dirigido a Entebbe. Ahí se les unieron otros tres secuestradores. El 1 de julio liberaron a un grupo importante de personas, pero mantuvieron a unos 100 rehenes. Lanzaron un ultimátum, amenazando con hacer explotar el aeropuerto y a los rehenes. Antes que ello ocurriera, tropas israelíes lanzaron una ofensiva, rescatando a los secuestrados que sobrevivieron pero falleciendo el líder de la operación, el Coronel Yonatan Netanyahu ${ }^{23}$.

Algunos países condenaron la actitud de Israel en el Consejo de Seguridad, como el representante de Guyana que calificó al raid como "una versión moderna de la diplomacia de las cañoneras" o el representante soviético que lo consideró como "un acto de

19 Márquez, María del Carmen. Problemas actuales sobre la prohibición del recurso a la fuerza en derecho internacional. Tesis para optar al Grado de Doctor, Facultad de Derecho de la Universidad de Sevilla, 1995, p. 132.

20 Además de los mencionados, las invasiones por parte de Estados Unidos en Granada (1983) y Panamá (1989) constituyen otros ejemplos ilustrativos sobre la cuestión.

21 La Crisis del Canal de Suez ocurrió cuando el 26 de julio de 1956, Gamal Abdul Nasser nacionalizó dicho canal, estallando la guerra en territorio egipcio. El conflicto implicó, por un lado, a la alianza entre Gran Bretaña, Francia e Israel, contra Egipto, por el otro.

22 KyLE, Keith K. Suez: Britain's end of Empire in the Middle East. Londres, IB Tauris, 1991, p. 390.

23 "On this day: 04 of July 1976". BBC News. [en línea] <http://news.bbc.co.uk/onthisday/hi/dates/stories/ july/4/newsid_2786000/2786967.stm> [consulta: 10 de junio de 2015]. 
agresión". Sin embargo, otros la valoraron, como lo demuestra la declaración de Estados Unidos: "Israel actuó dentro del marco de su derecho a usar la fuerza para proteger a sus nacionales de una amenaza inminente de lesiones o muerte en una situación en que el Estado en cuyo territorio se encuentran o no quería o no podia protegerlos" 24 .

Un tercer ejemplo es el denominado Incidente Mayagüez, que era un carguero americano que navegaba entre Vietnam del Sur y Tailandia a mediados de mayo de 1975, tres semanas después de la victoria de las fuerzas revolucionarias de Vietnam. Al acercarse a una isla de Camboya -donde acababa de tomar el poder un grupo revolucionario-, los camboyanos detuvieron el carguero e hicieron desembarcar a la tripulación. El Presidente Ford envió un mensaje al gobierno camboyano "para que pusiera en libertad al barco y su tripulación; tras 36 horas sin obtener respuesta, Ford empezó con las operaciones militares y los aviones estadounidenses bombardearon a los barcos camboyanos, entre ellos al barco que estaba transportando a tierra a los marineros americanos" 25 .

Como relata Ronzitti, Estados Unidos, después de lanzar el primer ataque, buscó apoyo en el Secretario General de Naciones Unidas, pero reservándose al mismo tiempo el derecho de "tomar las medidas que sean necesarias para proteger la vida de los ciudadanos y los bienes estadounidenses, incluidas las medidas apropiadas de defensa propia en virtud del articulo 51 de la Carta de la ONU'26.

El profesor González Campos sostiene que estos supuestos de las represalias armadas y la protección de las personas y los bienes de los nacionales que se encuentran en país extranjero, "constituyen formas de intervención asentadas en la práctica de ciertos Estados, apoyados por conceptos jurídicamente ambiguos, en consideraciones políticas y (...) en una concepción amplia de la legítima defensa (que comprendería la legítima defensa strictu sensu y el estado de necesidad), a la que se sienten proclives determinados países anglosajones de tradición intervencionista (...)"27. Por lo demás, la intervención armada para proteger a los nacionales que estén en peligro en el extranjero no se encuentra generalmente aceptada ${ }^{28}$.

En la mayoría de los casos mencionados se utilizó la protección de los nacionales para iniciar acciones de fuerza en contra de otro Estado, amparándose en una interpretación amplia de la legítima defensa. Algunos autores - minoritarios- afirman que un ataque a

24 Van Dervort, Thomas R. International law and organization: An introduction. Thousand Oaks (California), Sage Publications, 1997, p. 472. La traducción es nuestra.

25 Zinn, Howard. La otra historia de los Estados Unidos. New York, Seven Stories Press, 2011, p. 408.

26 Ronzitti, Natalino. Rescuing nationals abroad through military coercion and intervention on grounds of humanity. Dordrecht, Martinus Nijhoff Publishers, 1985, p. 36. La traducción es nuestra.

27 González Campos, Julio Diego; Andrés Sáez De Santamaría, María Paz; y Sánchez Rodríguez, Luis. Curso de Derecho Internacional Público. $2^{a}$ edición revisada. Madrid, Civitas, 2002, p. 879.

28 González, Andrés y Sánchez, Curso de Derecho Internacional..., op.cit., p. 880. 
Revista Tribuna Internacional

Volumen $4 \cdot \mathrm{N}^{0} 7 \cdot 2015 \bullet$ pp. 109-128

ISSN 0719-210X (versión impresa)/ISSN 0719-482X (versión en línea)

la población, al ser ésta un elemento constitutivo del Estado, aunque los nacionales se encuentren en el territorio de otro Estado, constituye un "ataque armado"29. La mayoría de los autores rechaza esta interpretación puesto que no se trata de un atentado contra la integridad territorial del Estado y la seguridad estatal tampoco queda en tela de juicio ${ }^{30}$.

No obstante, otros autores como Guerisoli señalan ciertos requisitos que debieran cumplirse para que las acciones de los Estados para rescatar a nacionales en peligro en el extranjero sean lícitas, a saber: "deben ser puntuales en razón de espacio y tiempo; limitadas y proporcionadas en los medios; supeditadas a la ineficiencia del sistema de seguridad colectiva de la Carta; huérfanas de la colaboración, en su caso, del Estado territorial a los efectos de resolver la situación conflictiva, y; encaminadas estrictamente a la protección de las vidas de las personas" ${ }^{\prime 31}$.

A mayor abundamiento, Franck agrega que, en caso de peligro para los nacionales, unido a la inacción de Naciones Unidas -por razones políticas-, "entonces un cierto uso de la fuerza por un Estado puede ser aceptada como legitima defensa en el sentido del articulo 51". Para ello, "la amenaza a los ciudadanos debe ser verdadera y grave; el motivo del Estado de intervenir se percibe como realmente protector; la intervención debe ser proporcional y de corta duración, y con daños colaterales minimos (...)"32.

\section{La intervención por invitación o con el consentimiento del Estado}

En la Joint Resolution, Estados Unidos afirma que "está trabajando con aliados y socios regionales y globales para degradar y derrotar al EI, para cortar su financiamiento, para detener el flujo de combatientes extranjeros de sus filas y para apoyar a las comunidades locales lo que rechazan". En este sentido, en junio de 2014, Estados Unidos aceptó la invitación

29 Vid. Bowett, Derek W. "The use of force for protection of nationals abroad", en Cassesse, Antonio (editor). The current legal regulation of the use of force. Dordrecht, Martinus Nijhoff Publishers, 1986, pp. 39-55; Dinstein, Yoram. War, Aggression and self-defense. $4^{a}$ edición. Cambridge, Cambridge University Press, 2005, pp. 200-201.

30 Vid. entre otros, Brownlie, Ian. International law and the use of force by states. Oxford, Clarendon Press, 1963, 560 p.; Fawcett, James Edmund Sandford, "Intervention in international law: A study of some recent cases", Recueil des Cours, vol. 103. La Haya, Académie de Droit International, 1961, pp. 343-423; AKehurst, Michael. "The use of force to protect nationals abroad". International Relations, vol. 5, № 5 , 1977, pp. 3-23; Schindler, Dietrich. "State of war, belligerency, armed conflict", en Cassese, Antonio (editor). The New Humanitarian Law of Armed Conflict. Napoles, Editoriale Scientifica, 1979, pp. 3-20; Simma, Bruno. "NATO, the UN and the Use of Force: Legal Aspects". European Journal of international law, vol. 10, $\mathrm{N}^{\circ} 1,1999$, pp. 1-22; RonzitTI, Rescuing nationals abroad..., op.cit.

31 Guerisoli, Emmanuel. Evolución del concepto de legítima defensa. Buenos Aires, Centro Argentino de Estudios Internacionales, 2009, p. 19. [en línea] <http://www.caei.com.ar/sites/default/files/19_6.pdf> [consulta: 10 de junio del 2015].

32 FRANCK, Thomas M. Recourse to force: State action against threats and armed attacks. Cambridge, Cambridge University Press, 2002, p. 96. La traducción es nuestra. 
lanzada por el Gobierno de Irak para apoyar a las fuerzas armadas de ese país y para luchar contra el Estado Islámico ${ }^{33}$. Este es un caso de la denominada "intervención por invitación” en que un Estado determinado extiende una invitación a otro(s), vale decir, otorgándole su expreso consentimiento para realizar acciones que implican el uso de la fuerza dentro de su territorio.

Uno de los casos más recientes fue el de Mali a principios del año 2012 aunque, como veremos, de manera equivocada. Contextualizando brevemente, en marzo de 2012 un grupo de militares derrocó al Presidente Amadou Toumani Touré a través de un golpe de Estado. La situación se tornó confusa y tres fuerzas armadas rivales se encontraban presentes: la Junta, que había tomado el poder en la capital Bamako; la rebelión Tuareg, que lanzaba una ofensiva en el norte del país; y el ejército regular, fiel al Presidente Touré. Aquel golpe de Estado se originó justamente por la Junta que acusaba al Presidente de ser incapaz de detener la ofensiva Tuareg desde enero de ese ańo ${ }^{34}$.

En este escenario, el Movimiento Nacional para la Liberación del Azawad (MNLA) ${ }^{35}$, con el sustento de grupos islamistas y éstos apoyados a su vez por miembros de Al Qae$\mathrm{da}^{36}$, luego de conquistar varias ciudades del norte de Mali, entre ellas, Kidal, Gao y Tombuctú, proclamó unilateralmente la secesión de la región de Azawad y la creación del Estado Islámico de Azawad. A finales de junio de ese año, las divisiones y tensiones entre los diferentes grupos tuaregs moderados e islamistas, principalmente el grupo salafista tuareg Ansar Dine, el Al Qaeda del Magreb Islámico (AQMI) y su escisión, el Movimiento por la Unidad y Yihad en África del Oeste (Muyao), así como la aplicación de la sharia (ley islámica) en las zonas conquistadas, contribuyeron a un mayor distanciamiento del MNLA y a la internacionalización del conflicto ${ }^{37}$.

El Presidente francés, François Hollande, declaró que Francia, a solicitud del Presidente de Mali y de conformidad con la Carta de las Naciones Unidas, se ha comprometido

33 U.S. Department of Defense. "DoD Authorizes War on Terror Award for Inherent Resolve Ops". [en línea] <http://www.defense.gov/news/newsarticle.aspx?id=123542> [consulta: 10 de junio del 2015].

34 Pellissier, Pauline. "Le point sur la situation au Mali en cinq questions". Le Monde, 02 de abril del 2012. [en línea] <http://www.lemonde.fr/afrique/article/2012/04/02/le-point-sur-la-situation-au-mali-en-cinqquestions_1678918_3212.html> [consulta: 10 de junio del 2015]. La traducción es nuestra.

35 Pellissier, "Le point sur...", op.cit. El apelativo "Tuareg de Azawad" designa al conjunto de Tuareg en la región de Azawad, situada al norte de Mali, al norte del río Níger. El MNLA exige la autodeterminación para esa región. Este movimiento fue creado en 2010 luego de fusionarse el Movimiento Nacional del Azawad (MNA) con un grupo de jóvenes intelectuales y militantes políticos, así como guerrilleros de la ExAlianza Tuareg-Níger-Mali (ATNM).

36 "Islamistas de Nigeria y miembros de Al Qaeda se unen a los rebeldes de Mali". El País, 10 de abril del 2012. [en línea] <http://internacional.elpais.com/internacional/2012/04/10/actualidad/1334066933_138268. html> [consulta: 10 de junio del 2015].

37 "Las claves de la rebelión en Malî". El País, 15 de enero del 2013. [en línea] <http://internacional.elpais. com/internacional/2013/01/11/actualidad/1357910558_300044.html> [consulta: 10 de junio del 2015]. 
a apoyar al ejército maliense para hacer frente a la agresión terrorista que amenaza a todo el África Occidental ${ }^{38}$. Por su parte, el Ministro de Asuntos Exteriores Laurent Fabius justificó legalmente la intervención militar francesa en dicho país argumentando, primero, que se realiza en respuesta a una solicitud hecha por el Gobierno legítimo de Mali, lo que se traduce en un caso de legítima defensa; segundo, por todas las respectivas resoluciones de Naciones Unidas; tercero, por la solicitud de la Comunidad Económica de Estados de África Occidental (CEDEAO o ECOWAS en su sigla en inglés) y, finalmente, por la posición adoptada por la Unión Africana ${ }^{39}$.

Los profesores Bannelier y Christakis analizaron estos argumentos. En cuanto al de la legítima defensa, amparado por el art. 51 de la Carta, indican correctamente que no nos encontramos frente a un caso de un ataque armado realizado por otro Estado en contra de Mali, ni tampoco estamos frente a un caso de "agresión indirecta", pues ni Francia ni Mali han invocado dicha teoría. En relación a la aplicación del art. 51 de la Carta en contra de las acciones realizadas por grupos privados sin conexión con otro Estado, como es el caso de los grupos terroristas, legalmente tampoco sería justificable dicha intervención pues no podría extenderse la noción de legítima defensa de modo tan controversial permitiendo a un Estado utilizar la fuerza en contra de su propia población. Señalan que "no hay necesidad de autorizar lo que ya está autorizado" pues, por un lado, todos los Estados tienen derechos soberanos en su territorio para desplegar fuerzas policiales o militares para reprimir actos de terrorismo y contrarrestar, dentro de los límites de los derechos humanos y/o las reglas del jus in bello, una insurrección armada o movimiento separatista ${ }^{40}$.

Por otro lado, el consentimiento otorgado por las autoridades malienses resulta a priori poderoso $^{41}$. Sin embargo, el Estado que acude en ayuda del Estado solicitante no posee un derecho ilimitado para su intervención pues, si el objetivo de la intervención es exclusivamente la resolución de un conflicto político interno en favor del gobierno

38 "Mali - Déclaration du président de la République, M. François Hollande, à l'issue du Conseil restreint de défense". París, 12 de enero de 2013. [en línea] <http://basedoc.diplomatie.gouv.fr/exl-php/cadcgp. php?CMD=CHERCHE\&QUERY=1\&MODELE=vues/mae_internet___recherche_avancee/home. html\&VUE=mae_internet___recherche_avancee\&NOM=cadic_anonyme\&FROM_LOGIN=1> [consulta: 10 de junio del 2015].

39 "Mali - Conférence de presse du ministre des affaires étrangères, M. Laurent Fabius". París, 11 de enero de 2013. [en línea] <http://basedoc.diplomatie.gouv.fr/exl-php/cadcgp.php?CMD=CHERCHE\&QUERY= $1 \& \mathrm{MODELE}=\mathrm{vues} / \mathrm{mae} \_$internet__recherche_avancee/home.html\&VUE=mae_internet__recherche_ avancee\&NOM=cadic_anonyme\&FROM_LOGIN=1> [consulta: 10 de junio del 2015].

40 Christakis, Theodore, y Bannelier, Karine. "French Military Intervention in Mali: It's Legal but... Why?", parte I y II, en EJIL: Talk! The blog of the European Journal of International Law, 24 de enero del 2013. [en línea] <http://www.ejiltalk.org/french-military-intervention-in-mali-its-legal-but-why-parti/\#more-7483> y <http://www.ejiltalk.org/french-military-intervention-in-mali-its-legal-but-why-part-2consent-and-unsc-authorisation/> [consulta: 10 de junio del 2015]. La traducción es nuestra.

41 Christakis y Bannelier, "French Military Intervention...", op.cit., parte II. 
autorizante, si bien en principio no estaría violando el art. 2(4) de la Carta de Naciones Unidas puesto que no se verifica un uso de la fuerza en contra de otro Estado sino que se trata de dos Estados cooperando y actuando conjuntamente, sí podría constituir una violación de los principios de no intervención en los asuntos internos de los Estados y del principio de auto-determinación de los pueblos. En el caso de Mali, dos de los tres grupos islámicos en contra de los cuales Francia ha intervenido son considerados como grupos terroristas ligados a Al Qaeda por el Consejo de Seguridad.

Finalmente, el tercer argumento francés dice relación con la autorización dada por el Consejo de Seguridad a través de la Resolución 2085 (2012). Si se leen conjuntamente los párrafos 7, 9, 11, 13 y 14 de dicha resolución, parece claro que el Consejo de Seguridad ha autorizado el uso de la fuerza ("todas las medidas necesarias") por parte de una Misión Internacional de Apoyo a Mali con Liderazgo Africano (AFISMA, en su sigla en inglés), al mismo tiempo que instó a los Estados miembros y a las organizaciones regionales e internacionales a que le presten su apoyo y "toda la asistencia necesaria en los esfuerzos para reducir la amenaza que representan las organizaciones terroristas (...)".

Mientras se esperaba el despliegue de la AFISMA y ante "la necesidad urgente de contrarrestar la creciente amenaza terrorista en Mali" con el objetivo de evitar una situación irreversible que podría comprometer totalmente la realización de la Resolución 2085, el Consejo de Seguridad instó a los Estados miembros a que "proporcionen a las Fuerzas Armadas y de Seguridad de Mali asistencia (...) con el fin de (...) reducir la amenaza que representan las organizaciones terroristas y sus grupos asociados" ${ }^{42}$.

En otras palabras, si bien en principio la intervención por invitación o con el consentimiento del Estado afectado no estaría violando el art. 2(4) de la Carta de Naciones Unidas -puesto que no se verifica un uso de la fuerza en contra de otro Estado, sino que se trata de dos Estados cooperando y actuando conjuntamente-, sí podría constituir una violación de los principios de no intervención en los asuntos internos de los Estados y del principio de auto-determinación de los pueblos. La base legal de la intervención francesa en Mali no viene dada ni por la legítima defensa (de otros) ni por la intervención consentida del Estado intervenido, sino que por la Resolución 2085 (2012) del Consejo de Seguridad que expresamente autorizó dicha intervención.

42 Consejo de Seguridad de Naciones Unidas. Resolución 2085 (2012), párr. 7. 
Revista Tribuna Internacional

Volumen $4 \cdot \mathrm{N}^{0} 7 \cdot 2015 \bullet$ pp. 109-128

ISSN 0719-210X (versión impresa)/ISSN 0719-482X (versión en línea)

\section{La intervención humanitaria: la Responsabilidad de Proteger}

La Joint Resolution expresa que el EI "ha amenazado con genocidio y ha cometido actos de violencia contra grupos religiosos y étnicos minoritarios, incluyendo a cristianos iraquies, a Yezidi y a las poblaciones de Turkmenistán”. Bajo esta afirmación subyace la denominada intervención humanitaria.

El argumento según el cual una acción militar destinada a salvar personas humanas no estaría en contradicción con el Derecho Internacional es de larga data ${ }^{43}$-pudiendo encontrarse en autores clásicos como Grotius, Vattel, Pufendorf, Suárez o Vitoria- y fue utilizado regularmente por los Estados sobre todo durante la segunda mitad del siglo $\mathrm{XIX}^{44}$. Con la adopción de la Carta de Naciones Unidas y la concretización del principio de prohibición del uso de la fuerza, el argumento resulta más difícil de sostener, aunque subsiste bajo la noción de "intervención humanitaria". Con la caída del Muro de Berlín y el fin de la Guerra Fría, emerge un "nuevo orden mundial” que garantizaría de mejor manera el respeto de los derechos humanos. El concepto de intervención humanitaria ha resurgido. Las crisis humanitarias en Somalia y Rwanda, así como la Guerra de Kosovo en la década de 1990, marcarán una nueva etapa en el debate, que desembocará en la noción de "Responsabilidad de Proteger" (R2P) ${ }^{45}$.

Éste deriva de la reformulación del concepto de intervención humanitaria que evocaba “(...) tradicionalmente la acción armada unilateral de Grandes Potencias en un tercer país, carente éste de poder político y -por lo general- sumido en un conflicto internacional o interno (...) estaban siendo o iban a ser objeto de lesiones muy graves y continuadas, en violación del Derecho Internacional, con la participación o ante la impotencia del Estado en cuestión” ${ }^{\sharp 6}$.

43 Murphy, Sean. Humanitarian intervention: the United Nations in an evolving world order. Philadelphia, University of Pennsylvania Press, 1996, pp. 33-64.

44 Domestici-Met, Marie José. “Aspects juridiques récents de l'assistance humanitaire”. Annuaire français de droit international, vol. 35, No 1. París, 1989, pp. 117-148.

45 El primer germen de la noción de Responsabilidad de Proteger podría corresponder al Informe sobre Desarrollo Humano presentado por el Programa de Naciones Unidas para el Desarrollo (PNUD) en 1994, que introdujo el concepto de "seguridad humana"; posteriormente, el entonces Secretario General de la ONU, Kofi Annan, pronunció el discurso de apertura de la Asamblea General de Naciones Unidas de 1999 cuando, en el contexto de la intervención militar en Kosovo por parte de la OTAN, acuñó el término de "intervención humanitaria" en virtud del cual las fronteras del Estado ya no debían ser vistas como protección impermeable para los criminales de guerra o los asesinos en masas. Por su parte, el art. 4 del Acta Constitutiva de la Unión Africana (2000) reconoce a esa organización el derecho a intervenir en el territorio de un Estado miembro en caso de crímenes de guerra, de genocidio y de crímenes contra la humanidad, así como el derecho de los Estados miembros a solicitar ese tipo de intervenciones.

46 Mariño, Fernando. "La responsabilidad de proteger: Una noción todavía ineficaz". Tiempo de paz, No 101. Madrid, 2011, p. 52. 
Durante la Cumbre Mundial de las Naciones Unidas de 2005, todos los Estados Miembros aceptaron oficialmente la responsabilidad de cada Estado de proteger a su población del genocidio, los crímenes de guerra, la depuración étnica y los crímenes de lesa humanidad. Los líderes mundiales ahí presentes también estuvieron de acuerdo en que cuando un Estado no cumpliera esa responsabilidad, la comunidad internacional es responsable de ayudar a proteger a las poblaciones amenazadas, utilizando primero los medios diplomáticos, humanitarios y otros medios pacíficos. Si esos medios resultan ser inadecuados y si "es evidente que las autoridades nacionales no protegen” a la población, la comunidad internacional debe actuar de manera "oportuna y decisiva" a través del Consejo de Seguridad y de conformidad con el Capítulo VII de la Carta ${ }^{47}$.

Por su parte, el Consejo de Seguridad de Naciones Unidas, en su Resolución 1674 (2006) sobre "Protección de los civiles en los conflictos armados", reconoció el principio al reafirmar estas disposiciones "respecto de la responsabilidad de proteger a las poblaciones del genocidio, los crimenes de guerra, la depuración étnica y los crimenes de lesa humanidad"48, pero reafirma en su segundo considerando, "su adhesión a los principios de la Carta enunciados en su Artículo 2 (párrafos 1 a 7 )" y a los propósitos de la Carta, declarándose dispuesto a adoptar las "medidas apropiadas" en caso de "violaciones sistemáticas, flagrantes y generalizadas del derecho internacional humanitario y de los derechos humanos en situaciones de conflicto armado" que "pueden constituir una amenaza para la paz y la seguridad internacionales" ${ }^{49}$.

Por de pronto, de acuerdo al Informe del Secretario General de Naciones Unidas titulado "Hacer efectiva la responsabilidad de proteger" de 2009, ésta descansa sobre tres pilares: la responsabilidad de proteger incumbe al Estado, la asistencia internacional y formación de capacidad y la respuesta oportuna y decisiva ${ }^{50}$.

En razón de una ausencia de reconocimiento, así como de una prohibición expresa, la doctrina que es favorable a la intervención humanitaria basa su argumentación en una interpretación a contrario de la última parte del art. 2(4) de la Carta: "Los Miembros de la Organización, en sus relaciones internacionales, se abstendrán de recurrir a la amenaza o al uso de la fuerza contra la integridad territorial o la independencia politica de

47 Cumbre Mundial de las Naciones Unidas de 2005, Reunión Plenaria de Alto Nivel del $60^{\circ}$ período de sesiones de la Asamblea General de las Naciones Unidas, Nueva York, del 14 al 16 de septiembre de 2005. En el documento final, los dirigentes mundiales acordaron adoptar medidas sobre varios desafíos mundiales, entre los cuales se incluyó el concepto de la Responsabilidad de Proteger. Vid. Documento Final de la Cumbre Mundial (2005), párr. 138 y 139. [en línea] <http://daccess-dds-ny.un.org/doc/UNDOC/GEN/ N05/487/63/PDF/N0548763.pdf?OpenElement> [consulta: 10 de junio del 2015].

48 Consejo de Seguridad de Naciones Unidas, Resolución 1674 (2006), párr. 4.

49 Consejo de Seguridad de Naciones Unidas, Resolución 1674 (2006), párr. 26.

50 Hacer efectiva la responsabilidad de proteger (2009) [en línea] <http://www.acnur.org/t3/fileadmin/ Documentos/BDL/2014/9612.pdf?view=1> [consulta: 10 de junio del 2015]. 
cualquier Estado, o en cualquier otra forma incompatible con los propósitos de las Naciones Unidas" $"$. De este modo, la prohibición del uso de la fuerza haría referencia sólo a ciertos objetivos, a saber, atentar contra la integridad territorial o la independencia política de un Estado o contra cualquier otro propósito de las Naciones Unidas. Pues si por definición la intervención humanitaria tiene como objetivo el respeto de los derechos humanos, siendo éste uno de los objetivos de las Naciones Unidas, se deduciría que la intervención humanitaria no sería incompatible con el art. 2(4) de la Carta ${ }^{52}$.

Pese a que podría aceptarse que esta interpretación a contrario contiene una cierta lógi$\mathrm{ca}$, de momento no resulta convincente. En relación a los principios de interpretación establecidos en la Convención de Viena sobre el Derecho de los Tratados, dicha interpretación resulta excesiva pues entra en conflicto con el "sentido corriente que haya de atribuirse a los términos del tratado" ${ }^{3}$. En efecto, parecería incompatible pretender que una acción armada llevada a cabo sobre el territorio de un Estado sin su consentimiento no resulte contraria a su integridad territorial ni a su independencia política ni que sea efectuada de manera incompatible con los propósitos de Naciones Unidas. En este sentido, incluso si una intervención humanitaria no tiene como objetivo derrocar al Gobierno de un Estado o modificar su régimen político, sería igualmente incompatible con el concepto de independencia en su contenido más esencial ${ }^{54}$. La única forma de intervención militar unilateral que no sería contraria a la integridad territorial ni a la independencia política de un Estado sería aquella en que dicho Estado otorga su consentimiento para dicha intervención ${ }^{55}$, considerando las observaciones hechas precedentemente sobre esta materia.

Si bien se reconoce una cierta práctica del Consejo de Seguridad autorizando acciones militares para poner fin a situaciones humanitarias dramáticas calificadas como amenazas contra la paz en el sentido de la Carta durante la década de 1990, el Documento Final de la Cumbre Mundial de 2005 no permite concluir que exista ninguna autorización a los Estados para intervenir unilateralmente en dichas situaciones, exigiéndose siempre la autorización del Consejo de Seguridad, lo que fue reiterado recientemente en la Resolución 1973 del 17 de marzo de 2011, en relación a la situación en Libia ${ }^{56}$.

51 La cursiva es nuestra.

52 Vid., por ejemplo, Stone, Julius. Aggression and world order: A critique of United Nations theories of aggression. Reimpresión. Clark (New Jersey), The Lawbook Exchange, 2010, p. 95; Lepard, Brian D. Rethinking Humanitarian Intervention. A Fresh Legal Approach Based on Fundamental Ethical Principles in International Law and World Religions. Pennsylvania, Pennsylvania State University Press, 2002, pp. 344-345.

53 Convención de Viena sobre el Derecho de los Tratados (1969), art. 31.1: "Un tratado deberá interpretarse de buena fe conforme al sentido corriente que haya de atribuirse a los términos del tratado en el contexto de éstos y teniendo en cuenta su objeto y fin".

54 RonzitTI, Rescuing nationals abroad..., op.cit., p. 8.

55 CORTEN, Olivier. Le droit contre la guerre: l'interdiction du recours à la force en droit international contemporain. París, Editions A. Pedone, 2008, p. 743.

56 Consejo de Seguridad de Naciones Unidas, Resolución 1973 (2011), párr. 4 
Por lo demás, la posición de ciertos grupos de Estados corrobora la conclusión anterior pues buscan principalmente respetar los mecanismos de seguridad colectiva previstos en la Carta. Así, los 115 Estados miembros del Movimiento de los No-Alineados reiteraron en 2005 y 2006 su 'rechazo al 'derecho' de intervención humanitaria, que no tiene base ni en la Carta de Naciones Unidas ni en el Derecho Internacional"57; el Grupo de Río estimó más en general que las disposiciones de la Carta siguen siendo pertinentes para regir todas las situaciones que amenazan la paz ${ }^{58}$; el Grupo de Georgia, Uzbekistán, Ucrania, Azerbaiyán y Moldavia (GUUAM) señala que "esas medidas sólo pueden adoptarse como último recurso y bajo el mandato explícito del Consejo de Seguridad"59; la Unión Europea expresó que "la comunidad internacional tiene la responsabilidad de decidir y de actuar, caso a caso y a través de una amplia gama de medidas, incluida la acción colectiva a través del Consejo de Seguridad, y en casos extremos y por necesidad, mediante el uso de la fuerza autorizada por el Consejo de Seguridad"60; y, finalmente, la práctica de algunos Estados se manifiesta en el mismo sentido ${ }^{61}$.

Por lo tanto, si existiese un "deber de asistencia humanitaria”, éste se enmarcaría necesariamente dentro de una esfera "moral" y no en el Derecho Internacional positivo, pues no se puede extraer de la práctica existente una opinio iuris que autorice la intervención unilateral de los Estados. No obstante, una tímida concepción de la "Responsabilidad de Proteger" ha emergido luego de 2005 en el seno de las Naciones Unidas, en caso de genocidio, crímenes de guerra, limpieza étnica y crímenes contra la humanidad, pero sólo en caso de negligencia absoluta de un Estado en relación a su obligación de proteger a su población de esos crímenes y, además, los medios de acción colectiva se encuentran limitados a los capítulos VI y VII de la Carta.

Con todo, el Secretario General de Naciones Unidas, en su informe titulado "La función de los mecanismos regionales y subregionales para hacer efectiva la responsabilidad de proteger" de 28 de junio de 2011, destaca que "propiciar una colaboración mundial-regional más efectiva es un elemento clave" para el nacimiento del principio de

57 Declaración del Embajador Rastam Mohd Isa, Representante Permanente de Malasia ante las Naciones Unidas y Chairman de la Oficina de Coordinación del Movimiento de los No-Alineados, en la Cuarta Reunión Informal en el Plenario de la 59ª Sesión de la Asamblea General de Naciones Unidas, 2005, párr. 16. La traducción es nuestra.

58 Asamblea General de las Naciones Unidas. Exchange of views on the President's draft outcome of the HighLevel Plenary Meeting of the General Assembly of September 2005 (A/59/HLPM/CPR.1).

59 Asamblea General de las Naciones Unidas. 59a sesión, 88a Reunión Plenaria, 7 de abril de 2005, (A/59/PV.88), p. 23. La traducción es nuestra.

60 Asamblea General de las Naciones Unidas. UK statement on behalf of the European Union, by H.E. Sir Emyr Jones Parry, Permanent Representative of the United Kingdom to the United Nations, at the Informal meeting of the plenary to discuss the revised text of the Draft Outcome Document of the High-level Plenary Meeting of the General Assembly, 28 July - 2 August, 2005, General Assembly. [en línea] <http://eu-un.europa. eu/articles/en/article_4974_en.htm> [consulta: 10 de junio del 2015].

61 Vid. Corten, Le droit contre..., op.cit., pp. 769-801. 
la responsabilidad de proteger. Además, se analizan sus límites y se proponen medidas que permitirían a la ONU reforzar la colaboración, información y análisis de organismos regionales y subregionales, con el objetivo de identificar signos de peligro y poder efectuar una acción preventiva eficaz. Concluye su informe señalando que "El apoyo al principio es amplio, profundo y cada vez mayor. Sin embargo, sabemos que declarar un principio y asegurar su aplicación coherente son dos cosas distintas. La aplicación del principio continuará siendo un ejercicio de aprendizaje para los Estados Miembros y la Secretaría. No tenemos todas las respuestas, pero estamos seguros de que el mejor camino para promover el principio de la responsabilidad de proteger es por medio de la colaboración mundial, regional y subregional"'62.

\section{Conclusiones}

La Joint Resolution presentada por el Presidente de Estados Unidos, Barack Obama, al Congreso norteamericano persigue la autorización del uso de la fuerza contra el denominado Estado Islámico (EI), basado en cuatro argumentos que buscan legitimar dicha intervención dentro de los márgenes establecidos por el Derecho Internacional. Sin embargo, no corresponde a los Estados calificar una situación de "amenaza para la paz y la seguridad internacionales", ya que tal determinación es competencia exclusiva del Consejo de Seguridad de Naciones Unidas.

Por otro lado, la interpretación amplia de la legítima defensa para la protección de nacionales se verifica en la práctica de ciertos Estados de tradición intervencionista, pero encuentra un rechazo en el resto de la comunidad internacional. Sin embargo, nada impide que en el futuro pueda eventualmente desarrollarse una práctica que legitime dichos actos, siempre y cuando se cumplan los requisitos generales y específicos analizados.

Por su parte, la intervención por invitación o con el consentimiento del Estado si bien, en principio, no estaría violando el art. 2(4) de la Carta de Naciones Unidas, puesto que no se verifica un uso de la fuerza en contra de otro Estado, sí podría constituir una violación de los principios de no intervención en los asuntos internos de los Estados y del principio de auto-determinación de los pueblos.

Finalmente, en cuanto a la intervención humanitaria y la Responsabilidad de Proteger, ni los documentos analizados ni la práctica del Consejo de Seguridad ni la práctica

62 Secretario General de Naciones Unidas. La función de los mecanismos regionales y subregionales para hacer efectiva la responsabilidad de proteger. 28 de junio de 2011. [en línea] <http://www.un.org/es/comun/ docs/?symbol=A/65/877> [consulta: 10 de junio del 2015]. 
Los argumentos estadounidenses para justificar el uso de la fuerza contra el Estado Islámico

Giancarlo Mosciatti Gómez

internacional permiten concluir la autorización a los Estados de intervenir unilateralmente en situaciones de crisis humanitarias.

Por lo tanto, ninguno de los argumentos esgrimidos por Estados Unidos en la Joint Resolution encuentra asidero en la práctica internacional actual. De momento, la legitimidad de las intervenciones que implican el uso de la fuerza deben, necesariamente, enmarcarse dentro de las excepciones al principio general del art. 2(4) de la Carta. Es decir, el sistema de seguridad colectiva y el derecho de legítima defensa constituyen las únicas respuestas lícitas a un ataque armado aceptadas por el Derecho Internacional actualmente. 